\title{
REFORMAS EDUCACIONAIS E RECONFIGURAÇÃO DA UNIVERSIDADE
}

\author{
EDUCATIONAL REFORMS AND UNIVERSITY RECONFIGURATION
}

\author{
Sarita Medina Silva ${ }^{1}$ \\ Luiza Vitória Vital Andrade ${ }^{2}$
}

\begin{abstract}
RESUMO: Este artigo tem por objetivo contextualizar o ensino superior evidenciando a conjuntura política educacional que reconfigurou a universidade brasileira a partir da década de 1990. Nesse sentido, foi apresentado um breve percurso do processo de desenvolvimento das políticas públicas educacionais que envolvem a reconfiguração da universidade e a democratização do acesso proposto pelas políticas de expansão do ensino superior, considerando as contradições quanto à proposição de avanços e os retrocessos. Assim, a finalidade deste texto é situar a dinâmica atual do funcionamento das universidades federais.

Palavras-chave: Reconfiguração da universidade pública. Ensino superior. Universidade Federal.
\end{abstract}

\begin{abstract}
This article aims to contextualize the higher education, highlighting the educational policy environment that reconfigured the Brazilian public university from the 1990s. That sense, a brief course of development processes of educational policies which involve the reconfiguration of the university was presented and the process of democratization of access proposed by the expansion of higher education policy, considering the contradictions concerning a proposed advances and setbacks. Thus, this article aims to situate the current dynamics of the operation of federal universities. Keywords: Rewriting the public university. Higher education. Federal University.
\end{abstract}

\footnotetext{
1 Doutora em Educação. Professora do Programa de Pós-Graduação em Educação da Universidade Federal de Uberlândia. sarita@ufu.br

2 Mestranda. Programa de Pós-Graduação em Educação da Universidade Federal de Uberlândia. luviviandrade@hotmail.com
} 


\section{Introdução}

Diante da conjuntura política e social dos anos 1990 e com o discurso de que o Estado estaria em crise, não conseguindo gerenciar bem as atividades do país, foi sugerida uma reformulação do aparelho estatal brasileiro. O Plano Diretor da Reforma do Aparelho do Estado proposto por Bresser Pereira nos anos 1990 recomendou a modernização da administração pública e o resgate da autonomia financeira e de seu poder de governança, definido como a "a capacidade de implementar de forma eficiente políticas públicas" (BRASIL, 1995b, p. 11). Nessa linha, o Estado passa a exercer função reguladora, deixando de ser o responsável direto pela promoção de bens e serviços. Reformar o Estado significou transferir para o setor privado as atividades que podiam ser controladas pelo mercado, dando início a um processo de privatização e publicização ${ }^{3}$ de serviços como a educação, a cultura, a saúde e a pesquisa científica que, uma vez classificados como serviços não exclusivos do Estado, puderam ser comercializados por instituições privadas (BRASIL, 1995b). Nessa perspectiva, a educação, antes direito concedido pelo Estado interventor por intermédio da Constituição Cidadã de 1988, agora se adéqua ao modelo neoliberal.

O neoliberalismo providenciou, consoante às exigências, uma adequação política e econômica de todos os mecanismos reguladores do país, sobretudo no que se refere à reestruturação produtiva. Enquadrando-se nisso, a Educação Superior passou por intenso processo de mercantilização, seja via ampliação de instituições privadas, seja via privatização de alguns serviços oferecidos pela universidade pública, com a cobrança de taxas de cursos e parcerias com empresas nas atividades de ensino, pesquisa ou extensão. Contudo, a reforma do Aparelho de Estado, ao permitir o comércio de alguns serviços da universidade pública, contraria o disposto na nossa Constituição Federal no que se refere à indissociabilidade entre ensino-pesquisa-extensão apresentada no artigo 207 (BRASIL, 1988). Conforme Catani e Oliveira (2002, p. 78),

[...] a indissociabilidade indicada visa a concretização de um padrão de qualidade na oferta da educação superior, assim como a limitação de fortes constrangimentos estatais, mercadológicos ou de outra natureza que consubstanciem dependência nos processos de ensino, de produção e de difusão de conhecimento.

Coincidentemente, esses processos estavam presentes e eram sugeridos pelo Banco Mundial em 1995, no documento "O Ensino Superior: as lições derivadas da experiência", e mais tarde, em 1996, também comporiam a LDB - Lei de Diretrizes e Bases da Educação e, em 2001, o PNE - Plano Nacional de Educação, conforme veremos a seguir.

\section{A universidade e as recomendações dos organismos multilaterais}

A reforma do Estado brasileiro constitui importante ponto de partida para a compreensão do processo de integração do país ao modelo transnacionalizado, com vistas à abertura do mercado interno para inserção na economia capitalista globalizada. A globalização da economia acentuada nos anos de 1990 provocou mudanças estruturais na sociedade, além de transformações no mundo do trabalho e nas políticas educacionais.

Com a definição de uma agenda política mundializada, na década de 1990, a educação adquire uma nova função social. Procuram-se incorporar novas reformas educacionais com a faceta gerencial, em vistas de uma rápida e almejada eficiência, os modelos e procedimentos do mercado para o interior do sistema

Conforme definição contida no documento do Plano Diretor da Reforma do Aparelho de Estado, a publicização trata da descentralização para o setor público não estatal da execução de serviços que não envolvem o exercício do poder de Estado, mas que devem ser subsidiados por ele (BRASIL, 1995b). 
educativo. (NAZÁRI, 2012, p. 39).

A educação passa então a incorporar o ideário neoliberal por meio das políticas educacionais empreendidas pelo Estado. Nesse contexto, percebe-se que várias diretrizes presentes nos documentos oficiais nacionais foram recomendadas pelas agências multilaterais. A exemplo disso cita-se a participação no campo educacional brasileiro, a partir da década de 1980, do Banco Mundial (BM) e de demais organismos internacionais, como o Banco Interamericano de Desenvolvimento (BID), importantes interlocutores multilaterais na propagação de novas orientações para o setor educacional (DOURADO, 2002).

Quanto à atuação desses organismos internacionais na educação, cumpre destacar o cenário que se configurou, a partir de 1944, na Conferência de Bretton Woods, realizada nos Estados Unidos pela Organização das Nações Unidas - ONU, no qual o BM teve sua vinculação ao Fundo Monetário Internacional - FMI, de forma que ambos deveriam auxiliar na reconstrução dos países após a II Guerra Mundial. A partir dos anos de 1950 o BM teve participação no processo de estabilização e expansão do sistema capitalista nos países do Terceiro mundo, também denominados de países em desenvolvimento, visto que com a iminência da Guerra Fria era interessante integrar esses países à aliança ocidental. Desde então o BM adquiriu e mantém o perfil de órgão de financiamento de países em desenvolvimento (SOARES, 2003).

Nas décadas de 1960 e 1970, com a continuidade da condição de pobreza, apesar dos avanços da economia dos países em desenvolvimento, veio por terra o pensamento predominante de que a miséria seria resultado da condição econômica do país e, portanto, desapareceria com seu crescimento. Em consequência, o BM passou a investir em outros setores da economia, como agricultura, infraestrutura e setores sociais. Já nos anos de 1980 os programas de ajuste estrutural conferiram ao BM importância estratégica junto aos países em desenvolvimento, tornando-o o "guardião dos interesses dos grandes credores internacionais, responsável por assegurar o pagamento da dívida externa e por empreender a reestruturação e abertura dessas economias, adequando-as aos novos requisitos do capital globalizado" (SOARES, 2003, p. 21). Entretanto, como contrapartida à assinatura dos empréstimos eram exigidas adequações políticas e econômicas dos países endividados. Uma vez comprometidos, para que fosse possível a obtenção de novos empréstimos, o BM passou a influenciar diretamente na formulação das políticas internas e na legislação desses países.

Dando seguimento a esse processo, em 1989 o Consenso de Washington consagrou as necessidades do capital internacional. Assim, o equilíbrio orçamentário mediante redução de gastos públicos, a abertura comercial pela redução tarifária e a eliminação de barreiras não tarifárias, a liberalização financeira, a desregulamentação dos mercados internos pela eliminação dos instrumentos de intervenção Estatal e a privatização de empresas e serviços públicos se configurariam como eixos principais desse procedimento (SOARES, 2003).

Diante desse cenário, a Organização das Nações Unidas para a Educação, a Ciência e a Cultura - Unesco, o Fundo das Nações Unidas para a Infância - Unicef e a Organização das Nações Unidas ONU ganharam espaço e se posicionaram sobre a atuação econômica, afirmando que esta só seria possível se andasse lado a lado com o desenvolvimento humano via ações políticas. Sendo assim, a partir da década de 1990 foi dada maior ênfase ao combate à pobreza nos financiamentos concedidos pelo BM. Entretanto, o BM não mudou o eixo central de sua política macroeconômica, não alterou o caráter excludente das políticas de ajustes e, no que se refere ao social, o financiamento continua voltado para programas sociais compensatórios, com vistas a dar suporte político e a garantir o padrão de crescimento econômico liberal (SOARES, 2003). Desta forma, evidencia-se que não foi objetivo do BM a melhoria efetiva das condições de vida da população, mas apenas que essa condição não interferisse tão incisivamente na economia ou na implantação das medidas atribuídas ao país devedor. A partir de 1995, na tentativa de executar programas sociais focalizados na população pobre, o BM passou a dar ênfase especial à educação (SOARES, 2003). Todavia, a educação era tida como instrumento de redução da pobreza via formação de capital humano, ou seja, via formação de 
pessoal adequado para o mercado de trabalho e não como meio de empoderar a sociedade.

Sendo assim, conforme afirma Coraggio (2003, p. 95), "a análise econômica transformouse na metodologia principal para a definição das políticas educativas". Assim, o BM induziu, entre outros, a descentralização do sistema educativo e o desenvolvimento das capacidades básicas de aprendizagem a fim de satisfazer a demanda por trabalhadores flexíveis (CORAGGIO, 2003). Para tanto, pregava que deveria haver investimento maciço do Estado na educação básica a fim de garanti-la a toda população, de modo que até os mais pobres pudessem acessá-la.

Para que fosse possível esse investimento na educação básica foi recomendado pelo BM, diante da escassez de recursos para esse fim, a realocação das verbas destinadas ao ensino superior e técnico para esse nível de ensino. Desse modo, caberia à iniciativa privada o preenchimento da lacuna deixada nas demais modalidades e níveis educacionais (CORAGGIO, 2003). Diante disso, começou um processo de amoldamento político da legislação educacional, de modo a estabelecer as diretrizes necessárias à sua efetivação.

Em continuidade ao estabelecido para o setor educacional, dentre as sugestões dos organismos internacionais estão a elevação da qualidade do ensino e o apontamento de mecanismos para a reorganização do sistema educacional. Essas diretrizes estão presentes, por exemplo, na LDB (1996) e no PNE (2001). O Estado brasileiro, nesse panorama, ao aderir aos empréstimos financeiros oferecidos por esses organismos multilaterais assume a adoção das instruções impostas pelo Banco Mundial.

Nessa perspectiva, conforme destaca Dourado (2002, p. 238),

Das orientações gerais do Banco Mundial é possível depreender a prescrição de políticas educacionais que induzem as reformas concernentes ao ideário neoliberal, cuja ótica de racionalização do campo educativo deveria acompanhar a lógica do campo econômico, sobretudo a partir da adoção de programas de ajuste estrutural.

As políticas educacionais acabaram sendo fortemente direcionadas, tanto na definição de suas prioridades quanto de suas estratégias, pelas orientações dos organismos internacionais financiadores, principalmente pelo BM. O poder crescente dos bancos, no âmbito político-educacional, obrigou os Estados nacionais a se adaptarem aos ritmos impostos pela Reforma, provocando a adoção de mudanças vertiginosas na área para não serem punidos (KRAWCZYK, 2000, p.3).

Esse discurso, juntamente com as propostas do BM, parece ter reduzido o processo de formação a uma visão restrita, de racionalidade instrumental, que acabou por acarretar em um redirecionamento da educação profissional e numa crescente privatização do ensino superior (DOURADO, 2002). Essas premissas geraram um aprofundamento da mercantilização da educação. Para o BM, conforme destaca Sguissardi (2009), esse nível de ensino não poderia ser tratado como um bem estritamente público em razão da sua condição de competitividade em virtude da oferta limitada; da excluibilidade, que torna possível a obtenção pela compra; e da recusa, uma vez que não é requerido por todos. Assim, as recomendações do Banco Mundial, no documento La enseñanza superior: las leciones derivadas de la experiencia (1995), propõem como 'estratégias' para esse nível de ensino a diversificação das instituições de ensino superior e das fontes de financiamento das universidades públicas, redefinindo a função do governo no ensino superior e defendendo a cobrança de matrículas e mensalidades e a venda de serviços educacionais como consultorias e pesquisas (BANCO MUNDIAL, 1995).

Em 1997, o BM lança ainda o documento "Relatório sobre o desenvolvimento mundial", em que trata especificamente da reformulação do papel do Estado. No prefácio do relatório, o então presidente do Banco Mundial, James D. Wolfensohn, coloca que naquele momento o "desafio do Estado consiste não em encolher-se até se tornar insignificante, nem em dominar os mercados, mas em dar esses pequenos passos" (BANCO MUNDIAL, 1997, p. IV). As reflexões contidas nesse rela- 
tório afirmavam o caráter minimalista de atuação do Estado, reforçando a ideia do mercado como gestor da vida social. Ao propor um reordenamento da função do Estado, o BM estabelece algumas estratégias para que essas instituições funcionem melhor. Dentre elas estão ajustar a função do Estado à sua capacidade, defendendo que a atuação deste se concentre nos elementos fundamentais a fim de aumentar a eficiência de sua intervenção, visto que "fazer demasiado com poucos recursos e pouca capacidade muitas vezes acaba gerando mais danos do que benefícios" (BANCO MUNDIAL, 1997, p.3), e aumentar a capacidade do Estado revigorando as instituições públicas. Isso significa

sujeitar as instituições públicas a uma concorrência maior, a fim de aumentar a sua eficiência. Significa melhorar o desempenho das instituições, melhorando os salários e incentivos. E significa fazer com que o Estado seja mais sensível às necessidades da população, aproximar mais o governo do povo, mediante uma maior participação e descentralização (BANCO MUNDIAL, 1997, p. 4).

O referido relatório não só propõe a redefinição do papel do Estado como também estabelece um passo a passo com o objetivo de induzir a um intenso processo de privatização dos serviços públicos, incluindo a educação, em especial a superior.

Em consonância com essa orientação, em 2002 o BM lança o documento Construir sociedades de conocimiento: nuevos desafíos para la educación terciaria. Esse documento se tornou uma importante referência da intensificação da mercantilização da educação superior, deslocando a concepção de educação superior para a de educação terciária, prevendo o aprofundamento da diversificação das instituições de ensino superior, inclusive com a diversificação também de suas fontes de financiamento (BANCO MUNDIAL, 2002).

Como se vê, houve um estímulo à diversificação e ao crescimento das instituições universitárias, sobretudo no setor privado, sob o pretexto de proporcionar uma maior oferta de vagas nesse nível de ensino. Nessa perspectiva, a universidade pública precisou se readequar: de instituição social, passou a ser definida como organização social, apresentando-se na perspectiva operacional definida por uma prática social determinada de acordo com sua instrumentalidade (CHAUÍ, 2003). Sob essa nova configuração, as universidades brasileiras que transitavam pelos modelos clássicos napoleônico ou humboldtiano passaram também a adotar os modelos de ocasião, denominados de "Universidade mundial do Banco Mundial", caracterizados pela heteronomia, competitividade e neoprofissionalismo (SGUISSARDI, 2009, grifo nosso).

\section{Reconfiguração da universidade}

Consoante ao contexto político da época, diante das proposições da reforma do Estado e dos acordos com os organismos internacionais, ainda na década de 1990 foram balizadas alterações jurídicas e institucionais na área educacional a fim de formalizar a reconfiguração da educação com ênfase no ensino superior, conforme proposição deste texto.

A Conferência Educação para Todos ocorrida em Jomtien - Tailândia, no ano de 1993, teve forte influência na composição legislativa educacional. Essa conferência teve por objetivo estabelecer compromissos em escala mundial para garantir que todas as pessoas tivessem acesso aos conhecimentos básicos a fim de ter uma vida mais digna, considerada condição para uma sociedade mais humanizada e justa. Nesse evento, os organismos voltados aos direitos humanos, como a Unesco, a Unicef e a ONU, com apoio do BM, ganharam pauta na discussão do desenvolvimento humano, estabelecendo ações nas áreas sociais, em especial na educacional. O capital parece ganhar um contraponto humanizador. Por meio das discussões ocorridas nessa conferência foi formulado o documento "Declaração Mundial sobre Educação para Todos", contendo definições sobre as necessidades de aprendizagem, metas a serem atingidas e compromissos dos governos e demais entidades participantes, como as Organizações Não Governamentais (ONGs) e a Organização da Sociedade 
Civil de Interesse Público (Oscip), que compõem o chamado Terceiro Setor ${ }^{4}$. Todos os países foram incentivados a elaborar planos que contemplassem as diretrizes e metas contidas na Declaração Mundial sobre Educação para Todos.

Em decorrência dos compromissos assumidos na Conferência Educação para Todos, foi elaborado o Plano Decenal de Educação para Todos, com atuação prevista para os anos de 1993 a 2003. "O Plano Decenal de Educação para Todos foi concebido para ser um instrumento de lutas e alianças em prol da recuperação da educação básica, acima de partidos e de ideologias" (BRASIL, 1993, p.4) e estabelece como metas globais para o período a que se propõe:

- incrementar, em cerca de $50 \%$, os atuais níveis de aprendizagem nas matérias do núcleo comum, tomando como referência os novos padrões de conteúdos mínimos nacionais e de competências básicas a serem determinados para o sistema;

- elevar a, no mínimo, 94\% a cobertura da população em idade escolar;

- assegurar a melhoria do fluxo escolar, reduzindo as repetências, sobretudo na 1a e 5a séries, de modo a que $80 \%$ das gerações escolares, do final do período, possam concluir a escola fundamental com bom aproveitamento;

- criar oportunidade de educação infantil para cerca de 3,2 milhões de crianças do segmento social mais pobre;

- proporcionar atenção integral a 1,2 milhões de crianças e adolescentes através do Programa Nacional de Atenção à Criança e ao Adolescente (PRONAICA), em áreas urbanas periféricas;

- ampliar o atendimento de jovens e adultos, priorizando a faixa de 15 a 19 anos, de modo a oferecer oportunidades de educação básica equivalente a quatro séries para 3,7 milhões de analfabetos e 4,6 milhões de subescolarizados (BRASIL, 1993, p. 7).

Tais compromissos compuseram ainda o Plano Nacional de Educação para todos e posteriormente produziram a LDB, em 1996, e o PNE, em 2001 (LIMA, 2012). Tanto a LDB quanto o PNE foram decisivos para as mudanças estruturais e a intervenção estatal no nível de ensino superior.

A LDB de 1996, pensada e discutida na década de 1980, mas aprovada na década de 1990, consolida e amplia o dever do poder público com a educação em geral, em particular com o ensino fundamental, reforçando os objetivos do Plano Decenal de Educação. Analisando suas diretrizes, a proposta de "Educação para Todos" parece apenas compor um slogan, visto que no plano legal a LDB contribui para a ruptura do projeto educacional construído socialmente na década de 1980. Sutilmente, a proposta aprovada em 1996 transferiu responsabilidades que seriam do Estado para a sociedade e demais instituições, fossem elas familiares, privadas ou filantrópicas, redefinindo o papel do Estado. Percebe-se que a LDB, outorgada na década de 1990, em consequência do contexto da época, foi marcada pelas orientações internacionais de um modelo de política neoliberal em que o mercado era o regulador. Neste sentido, conforme coloca Lima $(2012$, p. 53):

A educação embutiu elementos marcados por valores de mercado. Velhos princípios de equidade social foram ressignificados. Participação, autonomia, descentralização foram metamorfoseados de uma natureza política para uma natureza econômica. A ênfase econômica suplantou o papel de organização po-

\footnotetext{
4 O Terceiro Setor é assim denominado por não pertencer nem ao setor privado nem ao setor público, mas por receber verbas de ambos os setores visando suprir as falhas da atuação destes. São instituições de natureza jurídica privada sem fins lucrativos, criadas e mantidas pelo trabalho voluntário, imprimindo um caráter filantrópico às suas atividades. Para Paoli (2002, p. 386), “ao mesmo tempo esta filantropia empresarial organizada adapta-se com vantagens às formas do lucro empresarial, e, deste prisma, ecoa o discurso neoliberal que preconiza a iniciativa individual e privada contra a ineficiência burocrática do Estado e a politização dos conflitos sociais".
} 


\begin{abstract}
lítico-social, construído na década de 1980, e passou a legitimar um modelo de Estado e de Educação que prima por movimentos de participação, autonomia e descentralização financeira. Isso muda sobremaneira o referencial de democratização e democracia; a participação não se configura, nesse movimento, como elemento primordial da democracia, mas como elemento de manutenção da educação sob intervenção do Estado em relação ao seu controle. As perspectivas de avaliação e de currículo serão, pois, esboçadas, planejadas, controladas pelo Estado [...].
\end{abstract}

Em continuidade a esse pensamento, pode-se dizer que a LDB se constitui em marco de referência para o início do processo de reestruturação da educação superior, servindo de arcabouço legal para a ampla reforma iniciada pelo governo Fernando Henrique Cardoso (FHC) com vistas à mudança de panorama da educação brasileira, em particular a superior. A reforma proposta pelo governo tinha por finalidade alterar o modelo que vinha sendo implantado desde a reforma de 1968 com a Lei $n$ ㅇ 5.540, e mesmo desconsiderar a Carta Magna brasileira a fim de introduzir modificações concretas nos padrões de avaliação, financiamento, gestão, currículo e produção do trabalho acadêmico, alterando significativamente a identidade das universidades. Assim, de acordo com Catani e Oliveira (2002, p. 78), a LDB é

o instrumento legal que melhor expressa os parâmetros e a lógica da reestruturação da educação superior implementada pelo governo FHC, já que a Constituição antecede a esse governo e foi produzida em um contexto de redemocratização do país.

No que se refere ao conteúdo da LDB para a educação superior, em linhas gerais, os artigos 43 a 57 estabelecem as finalidades, a abrangência, o oferecimento de cursos noturnos com igual qualidade dos diurnos, a diversificação de instituições, a participação do setor privado, entre outras questões relacionadas à autonomia universitária, ao quadro profissional e à avaliação institucional. Os artigos 43 a 50 tratam da educação superior de modo geral, versando sobre a diversificação das modalidades nesse nível educacional, permitindo a criação de cursos sequenciais, como os chamados tecnólogos que, com duração média de dois anos, são reconhecidos como curso superior. Os artigos 51 a 57 se referem mais especificamente às instituições universitárias. Ao analisar esses artigos, partilha-se das análises de Catani e Oliveira (2002, p. 82):

O padrão da grande universidade, pautada pela indissociabilidade entre ensinopesquisa-extensão como modelo de expansão para a educação superior, não foi mantido. Em seu lugar, começou a ganhar forma na LDB um sistema mais diversificado e diferenciado. Conforme a lei, a educação superior pode ser ministrada em IES, públicas e privadas, com variados graus de abrangência ou especialização (Art. 45), por meio de universidades e instituições não-universitárias (Art. $48, \S 1)$.

A reforma da educação imposta pela reforma do Estado acentua um caráter avaliativo, no qual o controle dos resultados é estrategicamente colocado. Neste sentido, a avaliação da educação superior funciona como instrumento que visa garantir os produtos de uma instituição e, ao longo do tempo, tem se configurado em diferentes propostas. Essas propostas, colocadas cada qual em um contexto político, refletem ideologias e evidenciam a complexidade desse nível de ensino em virtude do impacto que gera na sociedade. De acordo com a LDB, a avaliação institucional se coloca como parte da gestão das instituições de educação superior. Desta forma faz parte, de maneira enfática, das políticas universitárias dos governos e dos organismos internacionais de financiamento, passando a ter impacto nas exigências de regulação e de controle estatal (RODRIGUES, 2012). Portanto, está vinculada à lógica neoliberal, em estreita articulação com o sistema globalizado. 
Diante desses aspectos, percebe-se que a LDB "sugere uma reforma universitária estruturada em torno de dois grandes eixos: a avaliação e a autonomia" (CATANI; OLIVERIA, 2002, p. 84), buscando o controle dos resultados e a ideia de flexibilidade. Além disso, proporcionou à educação superior um estilo empresarial em detrimento do comprometimento com o caráter de transformação social, uma vez que possibilita que a universidade seja apresentada como uma organização social.

Como organização social, a universidade passa a ser regida pelas ideias de gestão, planejamento, previsão, controle e êxito. Nessa expectativa operacional, Chauí (2003) referencia a sociedade do conhecimento como aquela que transforma a ciência em produto, visto que passa a ser regida pela lógica do mercado, levando à heteronomia da universidade. Um sinal disso pode ser percebido pelo critério de avaliação, que passa a ser determinado pela eficácia e pela competitividade (CHAUÍ, 2003).

A questão da avaliação do ensino superior também foi contemplada na Lei no 9.131/95 que antecede a LDB e estabelece a criação do Conselho Nacional de Educação - CNE em substituição ao Conselho Federal de Educação. O CNE, composto pelas câmaras de Educação Básica e de Educação Superior, teria atribuições normativas, deliberativas e de assessoramento ao Ministério da Educação. Analisando as atribuições da Câmara de Educação Superior no artigo 9, parágrafo 2, é possível observar que a avaliação é uma constante em quase todas as alíneas.

Além disso, são colocadas como atribuições no parágrafo desse artigo também a análise de questões relativas à aplicação da legislação da educação superior, a deliberação de regimento e estatutos das instituições educacionais de nível superior e a indicação de sugestões para a elaboração e execução do PNE, outorgado somente seis anos depois (BRASIL, 1995a). Todavia, algumas das atribuições da Câmara de Educação Superior foram suplantadas pela Lei 10.861/2004, que instituiu o Sistema Nacional de Avaliação da Educação Superior, ficando cada vez mais evidente a gestão por resultados.

O Plano Nacional de Educação, estabelecido pela Lei no 10.171/2001, visava à instalação de um plano que tratasse da educação em todos os níveis em todo o território brasileiro. Após algumas propostas surgidas nas décadas anteriores, revisões foram sugeridas e, diante do estabelecido na LDB de 1996, que diz que a União deveria encaminhar o Plano ao Congresso Nacional "um ano após a publicação da citada lei, com diretrizes e metas para os dez anos posteriores, em sintonia com a Declaração Mundial sobre Educação para Todos", foi iniciada sua tramitação em 1998 e, em 2001, foi finalmente aprovado (BRASIL, 1996).

Com o objetivo de elevar o nível de escolarização da população melhorando a qualidade do ensino, reduzindo as desigualdades sociais a fim de estabelecer a permanência no sistema educacional e estabelecendo a democratização da gestão do ensino público, o PNE estabelece como diretriz básica para o ensino superior a autonomia universitária, conforme previsto na Constituição de 1988, e afirma que "nenhum país pode aspirar a ser desenvolvido e independente sem um forte sistema de educação superior", uma vez que "a produção de conhecimento, hoje mais do que nunca, tende a ser cada vez mais a base do desenvolvimento científico e tecnológico e que este é que está criando o dinamismo das sociedades atuais" (BRASIL, 2001b, p. 41).

Em 2014 foi aprovado o novo PNE para o decênio 2014-2024, trazendo diretrizes, metas e estratégias semelhantes ao anterior para todos os níveis educacionais. As metas 12, 13 e 14 tratam especificamente da educação superior e pretendem, em linhas gerais, elevar a taxa de matrícula na educação superior entre a população de 18 a 24 anos, ampliar a atuação de mestres e doutores nas instituições que tratam desse nível de ensino e elevar o número de matrículas na pós-graduação (BRASIL, 2014).

Por serem as universidades instituições concentradoras de pesquisas e do desenvolvimento científico e tecnológico em nosso país, a educação superior passou a ter enfoque nas políticas internas de governo, bem como nas recomendações dos organismos internacionais. Um dos principais documentos que demonstram a finalidade da educação superior a partir da década de 1990 e que busca traçar estratégias a serem implantadas nos anos posteriores é a "Declaração Mundial Sobre 
Educação Superior no Século XXI" organizada pela Unesco, marco da Conferência Mundial sobre Educação Superior ocorrida em Paris, em outubro de 1998.

Essa conferência visou dar respostas aos desafios e às necessidades da Educação Superior, lançando ideias e ações para o século XXI, de modo que o documento resultante propõe mudanças nesse nível de ensino mundial que vão ao encontro das transformações sociais, culturais e econômicas do referido século. Enfatizou ainda a necessidade de a universidade aumentar sua capacidade de mudar e provocar mudanças para "atender as necessidades sociais e promover a solidariedade e igualdade", preservando o rigor científico e colocando os estudantes no centro de suas preocupações, a fim de permitir que se integrem na sociedade de conhecimento global do novo século (UNESCO, 1998, p. 14). Além disso, conclamou todos a participarem da responsabilidade com a educação superior, tanto o indivíduo quanto os setores públicos e privados. A Unesco (1998), assim como os organismos internacionais, afirma que a diversificação institucional é uma forma de ampliar a igualdade de oportunidades.

\begin{abstract}
A diversificação de modelos de educação superior e dos métodos e critérios de recrutamento é essencial tanto para responder à tendência internacional de massificação da demanda como para dar acesso a distintos modos de ensino e ampliar este acesso a grupos cada vez mais diversificados, com vistas a uma educação continuada, baseada na possibilidade de se ingressar e sair facilmente dos sistemas de educação. (UNESCO, 1998, p. 20).
\end{abstract}

Assim, o Estado passa a não ser mais o único responsável pelo oferecimento desse nível de ensino, dividindo sua responsabilidade com os demais setores e órgãos governamentais e não governamentais, com a esfera privada ou mesmo com as entidades sem fins lucrativos. Agindo dessa forma, o Estado

\begin{abstract}
[...] se desobriga, portanto, de uma atividade eminentemente política, uma vez que pretende desfazer a articulação democrática entre poder e direito. Dessa maneira, ao colocar a educação no campo de serviços, deixa de considerá-la um direito dos cidadãos e passa a tratá-la como qualquer outro serviço público, que pode ser terceirizado ou privatizado (CHAUÍ, 2001, p. 177).
\end{abstract}

Evidencia-se, assim, a ressignificação do papel das instituições educativas, implicando alteração identitária das universidades. O movimento de transformação que redefine a identidade atual das universidades determina novas funções para o ensino superior. A diversificação institucional desse nível de ensino, eixo básico das propostas dos organismos internacionais, passou também a nortear os processos de expansão da educação terciária brasileira, de modo que esta foi considerada como imprescindível. Diante das reformulações sofridas pelo ensino superior, nos primeiros anos do novo século foi iniciada a expansão da universidade como processo de democratização do acesso a esse nível de ensino.

\title{
A "democratização" do Ensino Superior: processos de expansão da universidade
}

Já nos primeiros anos do século XXI um intenso conjunto de leis, decretos e medidas provisórias formalizaram os instrumentos jurídicos das reformulações da educação superior. Essa ação visava ao fortalecimento do empresariamento da educação superior, à implementação das parcerias público-privadas, à operacionalização dos contratos de gestão, eixos condutores da reforma do Estado brasileiro tanto no governo de FHC quanto de Lula, bem como à garantia da coesão social em torno das reformas estruturais realizadas por ambos.

O fortalecimento do empresariamento da educação superior se deu pela oferta desse nível de ensino nas instituições privadas e pela mercantilização de alguns serviços da universidade públi- 
ca. As instituições privadas, diante da permissão e configuração da diversificação institucional, via de regra oferecem o serviço de ensino, deixando a cargo da universidade pública o investimento em pesquisa e extensão. Tornou-se comum o surgimento de outras modalidades institucionais de ensino, como os centros universitários, as faculdades, integradas ou isoladas, os institutos e os centros de educação tecnológica. Conforme o PNE (BRASIL, 2001a, p. 41-42):

o sistema de educação superior deve contar com um conjunto diversificado de instituições que atendam a diferentes demandas e funções. Seu núcleo estratégico há de ser composto pelas universidades, que exercem as funções que the foram atribuídas pela Constituição: ensino, pesquisa e extensão. Esse núcleo estratégico tem como missão contribuir para o desenvolvimento do País e a redução dos desequilíbrios regionais, nos marcos de um projeto nacional. Por esse motivo, estas instituições devem ter estreita articulação com as instituições de ciência e tecnologia - como, aliás, está indicado na LDB (art. 86). [...] A universidade é, simultaneamente, depositária e criadora de conhecimentos.

Com o intuito de materializar a proposta de expansão de vagas para o ensino superior, o governo de Luís Inácio da Silva (Lula) lançou um pacote de medidas para os setores públicos e privados. Considerando a trajetória de Lula, esperava-se uma guinada na educação superior. Entretanto, observou-se a continuidade dos processos já estabelecidos desde o governo FHC. Apesar disso, na gestão de Lula a educação superior voltou a ser alvo de investimentos e programas governamentais. Nesse contexto, foram instituídos programas de expansão para esse nível de ensino com vistas à democratização do acesso a ele. Aqui destacamos a Lei de Inovação Tecnológica no 10.973/2004, que dispõe sobre incentivos à inovação e à pesquisa científica e tecnológica no ambiente produtivo, o estabelecimento de parcerias entre universidades públicas e empresas; a Lei no 11.096, de 13 de janeiro de 2005, que instituiu o Programa Universidade para Todos - Prouni; os decretos no $5.800 / 2006$ e 5.622/2005, que tratam da política de educação superior na modalidade a distância, especialmente com a criação da Universidade Aberta do Brasil; o Decreto no 6.096, de 24 de abril de 2007, que instituiu o Programa de Apoio a Planos de Reestruturação e Expansão das Universidades Federais - Reuni; e a Lei no 12.711, de 29 de agosto de 2012, que trata da reserva de vagas/cotas nas instituições federais de ensino superior.

O Prouni, criado em 2004 pela Lei no 11.096/2005, tem por finalidade a concessão de bolsas de estudo integrais e parciais a estudantes de cursos de graduação e de cursos sequenciais de formação específica em instituições privadas de educação superior. Esse programa estaria voltado a estudantes que ainda não possuíssem formação em curso superior; que tivessem cursado o ensino médio em escolas públicas ou sob a condição de bolsistas na escola privada; a alunos portadores de deficiências; ou a professores da rede pública de ensino para os cursos de licenciatura, normal superior e pedagogia, destinados à formação do magistério da educação básica, independentemente da renda. O percentual de desconto das bolsas estaria condicionado à análise da condição socioeconômica per capita da família. Em contrapartida à concessão de bolsas, as instituições que aderissem ao programa receberiam isenção de tributos, tais como: Imposto de Renda das Pessoas Jurídicas; Contribuição Social sobre o Lucro Líquido; Contribuição Social para Financiamento da Seguridade Social e Contribuição para o Programa de Integração Social, tornando extremamente vantajosa a adesão ao Prouni (BRASIL, 2005b). Percebe-se que essa lei muito beneficiou a rede privada de ensino superior ao aumentar a oferta e, consequentemente, a demanda de estudantes à procura de formação com a contrapartida de diminuição ou isenção de tributos. Implantada como uma diretriz voltada ao social, acalentando as expectativas da população que se sentiu incluída diante da possibilidade de galgar um degrau a mais no setor educacional, o Prouni atende aos anseios sociais e está em conformidade com as indicações dos organismos internacionais e com as normativas do movimento neoliberal.

Aliado ao Prouni, aos alunos que não conseguiram bolsa de estudo ou que a conseguiram parcialmente, o governo, via Ministério da Educação, lançou a possibilidade de adesão ao Fundo 
de Financiamento ao Estudante do Ensino Superior - Fies. O Fies funcionaria como um crédito estudantil sem contrapartida do aluno durante o período de formação. Como todo financiamento, há um percentual de juros a ser acrescentado ao valor de custeio do curso pretendido solicitado pelo estudante. Entretanto, é atrativo o fato de o beneficiário do crédito estudantil só começar a pagar seu empréstimo após ter se graduado, com carência de dezoito meses, a fim de proporcionar a sua entrada no mercado de trabalho (BRASIL, 2001a). Essas e outras informações sobre o Fies podem ser facilmente acessadas no site ${ }^{5}$ do MEC que, com linguagem bastante simples e didática, explica o programa de financiamento utilizando o slogan "Quem acredita em si mesmo merece o nosso crédito" atraindo estudantes. Tanto o Prouni quanto o Fies dão à sociedade brasileira a sensação de assistência governamental aos setores sociais mais necessitados economicamente. Desta forma, exerce uma dupla função: atende ao mercado e à ideologia de atuação democrática da população.

O Prouni expressa a parceria público-privada na educação superior, uma vez que garante isenção fiscal para o setor privado em troca de "vagas públicas" nas instituições de ensino superior - IES privadas. A parceria público-privada também se expressa por intermédio da Lei de Inovação Tecnológica, viabilizando a associação entre instituições de ensino superior públicas e empresas, estimulando e apoiando a constituição de alianças estratégicas e o desenvolvimento de projetos de cooperação envolvendo empresas nacionais, Instituições Científicas e Tecnológicas e organizações de direito privado sem fins lucrativos voltadas para atividades de pesquisa e desenvolvimento que objetivem a geração de produtos e processos inovadores (BRASIL, 2004).

Ainda seguindo a proposta de aumentar a oferta de vagas no ensino superior e de diversificar as modalidades de ensino, os decretos $n=5.800 / 2006$ e $n=5.622 / 2005$, que tratam da política de educação superior na modalidade a distância e da criação da Universidade Aberta do Brasil - UAB, trazem novas possibilidades. A educação a distância é então caracterizada como uma modalidade na qual a mediação didático-pedagógica nos processos de ensino-aprendizagem acontece com a utilização de tecnologias de informação e comunicação em lugares ou tempos diversos, podendo ser ofertada em vários níveis e modalidades educacionais e pelas esferas públicas e privadas (BRASIL, 2005a).

No ano seguinte, voltada "para o desenvolvimento da modalidade de educação a distância, com a finalidade de expandir e interiorizar a oferta de cursos e programas de educação superior no País", é instituída a Universidade Aberta do Brasil pelo Decreto no 5.800/2006 (BRASIL, 2006a). A UAB cumpre sua finalidade mediante a oferta de cursos e programas de educação superior na modalidade a distância por instituições públicas de ensino superior articulada a polos de apoio presencial.

Independentemente das críticas ao processamento e à qualidade da modalidade de educação a distância, visto que não é o objetivo deste texto, há de se considerar que de fato ela proporciona formação aos estudantes pertencentes às comunidades mais isoladas e que teriam dificuldades físicas ou geográficas de frequentar uma instituição com aulas presenciais diariamente por meio da utilização dos novos processos de tecnologia e comunicação.É importante mencionar que as ações de expansão do ensino superior estão contidas no Plano de Desenvolvimento da Educação - PDE proposto pelo governo federal no ano de 2007. O PDE se constituiu em um pacote de medidas com metas e programas voltados à melhoria de todos os níveis de ensino sustentado em três eixos: gestão, financiamento e avaliação. Com relação ao ensino superior, o PDE baliza-se pelos princípios de expansão da oferta de vagas, da qualidade da oferta, da promoção da inclusão social pela educação, da ordenação territorial e do desenvolvimento econômico e social (BRASIL, 2008). Desta forma, a expansão e a reestruturação das universidades públicas federais, a ampliação do Prouni, a reformulação do Fies e do Sistema Nacional de Avaliação da Educação Superior - Sinaes constituem

\footnotetext{
5 As informações do Fundo de Fundo de Financiamento ao Estudante do Ensino Superior (Fies) podem ser acessadas no site do Ministério da Educação, no endereço: http://sisfiesportal.mec.gov.br/fies.html. Nele a população pode, de maneira bastante didática, obter informações de como funciona o programa, o passo a passo da inscrição, as condições de financiamento e o pagamento do empréstimo adquirido, simular o financiamento, consultar os cursos e instituições filiadas por região, acessar a legislação que o regulamenta e tirar dúvidas via telefone ou atendimento on-line.
} 
ações do PDE para o ensino superior, que devem também articulá-lo com a educação básica e a pósgraduação (BRASIL, 2008).

Assim, com relação à expansão e reestruturação das universidades públicas federais, um plano de expansão foi proposto e a primeira fase, denominada Expansão I, deu-se no período de 2003 a 2007. Nesse período foram criados novos campi e universidades federais com o objetivo de interiorizar a educação superior pública federal a fim de que a população que residia fora dos grandes centros também tivesse a oportunidade de formação universitária. Com essas medidas, pretendiase cumprir o disposto pelo PNE no que se refere ao provimento de oferta da educação superior para pelo menos 30\% dos jovens na faixa etária de 18 a 24 anos até o final da década (BRASIL, 2012).

Dando prosseguimento à proposta de expansão da universidade pública com base no Decreto no 6.096/2007, foi criado o Programa de Apoio a Planos de Reestruturação e Expansão das Universidades Federais (Reuni). Tendo por objetivo a criação de condições para a ampliação do acesso e a permanência na educação superior pública, o Reuni pregava um melhor aproveitamento das estruturas físicas e de recursos humanos existentes nas universidades federais e tinha por "meta global a elevação gradual da taxa de conclusão média dos cursos de graduação presenciais para noventa por cento e da relação de alunos de graduação em cursos presenciais por professor para dezoito, ao final de cinco anos, a contar do início de cada plano" (BRASIL, 2007a). Para que isso fosse possível, previa o adicional de $20 \%$ de recursos financeiros para cada universidade, condicionados à capacidade orçamentária e operacional do Ministério da Educação, para o suporte com as despesas decorrentes da adesão ao programa, tais como: construção e readequação de infraestrutura e equipamentos, compras de bens e serviços e despesas de custeio e de pessoal associadas à expansão das atividades (BRASIL, 2007b).

As reformas e políticas voltadas para a educação superior têm por objetivo a garantia da coesão social em torno das reformas estruturais realizadas pelo governo Lula, estando em harmonia com a recomendação das políticas dos organismos internacionais. Nesse sentido, considera-se necessário questionar se a democratização desse nível educacional atende ao seu propósito.

\section{Considerações finais}

Podemos sintetizar que as diversas reformas realizadas no ensino superior a partir dos anos de 1990 ocasionaram a reconfiguração da universidade pública federal, alterando a identidade e os processos de trabalho dessas instituições. O movimento de transformação que redefine a identidade atual das universidades determina novas funções para o ensino superior, e um dos frutos da ressignificação universitária se traduz nos processos de expansão desse nível de ensino.

Apesar de constituir importante referência política de ampliação de acesso utilizada habilmente pelo governo federal para legitimar suas ações por meio da manipulação do senso de democracia da população, considera-se que as políticas de expansão para o ensino superior, em especial as voltadas à educação pública, caracterizam-se como ganhos por proporcionar aos estudantes significativo aumento de possibilidade de acesso ao ensino superior. A expansão da educação superior é uma demanda legítima da sociedade e está em sintonia com os novos padrões de regulação e gestão desse nível de ensino. Verifica-se também que a interiorização dos campi e a criação de novas universidades contribuem para a democratização do acesso ao ensino superior e oportunizam o desenvolvimento de projetos de pesquisa e extensão mais específicos à população da região em que elas estão inseridas.

É inegável que o processo de reconfiguração da universidade, em especial a expansão, trouxe benefícios para a população em geral. $O$ aumento da oferta de vagas foi expressivo e as minorias não foram esquecidas: as novas políticas resguardaram seus direitos sob a forma de cotas. Entretanto, deve-se considerar que a universidade vem sofrendo alteração em sua identidade, cujas consequências podem interferir na dinâmica institucional como um todo. 


\section{Referências}

BANCO MUNDIAL. Construir sociedades de conocimiento: nuevos desafíos para la educación terciaria. Washington, 2002. Disponível em: <http://siteresources.worldbank.org/TERTIARYEDUCATION/Resources/Documents/ Constructing-Knowledge-Societies/CKS-spanish.pdf>. Acesso em: 20 out. 2013.

BANCO MUNDIAL. La enseñanza superior: las leciones derivadas de la experiência. Washington, 1995. Disponível em: <http://firgoa.usc.es/drupal/files/010-1344Sp.pdf>. Acesso em: 10 set. 2013.

BANCO MUNDIAL. Relatório sobre o desenvolvimento mundial: o Estado num mundo em transformação. Washington, 1997. Disponível em: <http://www.acervo.epsjv.fiocruz.br/beb/textocompleto/mfn11116>. Acesso em: 20 out. 2013.

BRASIL. Constituição (1988). Constituição da República Federativa do Brasil. Brasília, DF: Senado Federal, 1988.

BRASIL. Ministério da Educação. O que é o Plano Decenal de Educação para todos. Brasília, DF, 1993, 8 p. Disponível em: <http://biblioteca.planejamento.gov.br/biblioteca-tematica-1/textos/educacao-cultura/texto-167-oque-e-o-plano-decenal-de-educacao-para-todos.pdf>. Acesso: 20 ago. 2013.

BRASIL, Lei no 9131/95 de 24 de novembro de 1995. Altera dispositivos da Lei no 4.024, de 20 de dezembro de 1961, e dá outras providências. Brasília, DF, 1995a. Disponível em: <http://www.planalto.gov.br/ccivil_03/Leis/ L9131.htm>. Acesso em: 3 jul. 2013.

BRASIL. Ministério da Administração e Reforma do Estado. Plano Diretor da Reforma do Aparelho de Estado. Brasília, DF, 1995b.

BRASIL. Lei no 9.394, de 20 de dezembro de 1996. Estabelece as diretrizes e bases da educação nacional. Brasília, DF, 1996. Disponível em: <http://portal.mec.gov.br/arquivos/pdf/ldb.pdf>. Acesso em: 3 ago. 2013.

BRASIL. Decreto no 5.622 de 19 de dezembro de 2005. Regulamenta o art. 80 da Lei no 9.394, de 20 de dezembro de 1996, que estabelece as diretrizes e bases da educação nacional - modalidade à distância. Brasília, DF, $2005 a$. Disponível em: <http://www.planalto.gov.br/CCIVIL_03/_Ato2004-2006/2005/Decreto/D5622.htm>. Acesso em: 5 ago. 2013.

BRASIL. Decreto no 5.800 de 08 de junho de 2006. Dispõe sobre o sistema de Universidade Aberta do Brasil UAB. Brasília, DF, 2006a. Disponível em: <http://www.planalto.gov.br/ccivil_03/_Ato2004-2006/2006/Decreto/ D5800.htm>. Acesso em: 5 ago. 2013.

BRASIL. Decreto no 6.096, de 24 de abril de 2007. Institui o Programa de Apoio a Planos de Reestruturação e Expansão das Universidades Federais - REUNI. Brasília, DF, 2007a. Disponível em: <http://www.planalto.gov.br/ ccivil_03/_ato20072010/2007/decreto/d6096.htm>. Acesso em: 20 ago. 2013.

BRASIL, Lei $\mathrm{n}^{\circ}$ 10.260, de 12 de julho de 2001. Dispõe sobre o Fundo de Financiamento ao estudante do Ensino Superior e dá outras providências. Brasília, DF, 2001a. Disponível em: <http://www.planalto.gov.br/ccivil_03/ Leis/LEIS_2001/L10260.htm>. Acesso em: 6 ago. 2013.

BRASIL. Lei no 10.172, de 09 de janeiro de 2001. Aprova o Plano Nacional de Educação e dá outras providências. Brasília, DF, 2001b. Disponível em: <http://www.planalto.gov.br/ccivil_03/leis/leis_2001/l10172.htm>. Acesso em: 3 ago. 2013.

BRASIL. Lei $\mathrm{n}^{\circ} 10.973$, de 2 de dezembro de 2004. Dispõe sobre incentivos à inovação e à pesquisa científica e tecnológica no ambiente produtivo e dá outras providências. Brasília, DF, 2004. Disponível em: <http://www. planalto.gov.br/ccivil_03/_ato2004-2006/2004/lei/l10.973.htm>. Acesso em: 6 ago. 2013.

BRASIL. Lei no 11.096, de 13 de janeiro de 2005. Institui o Programa Universidade para Todos - PROUNI regula 
a atuação de entidades beneficentes de assistência social no ensino superior; altera a Lei no 10.891, de 09 de julho de 2004, e dá outras providências. Brasília, DF, 2005b. Disponível em: <http://www.planalto.gov.br/ccivil_03/_Ato2004-2006/2005/Lei/L11096.htm>. Acesso em: 05 ago. 2013.

BRASIL. Ministério da Educação/ Ministério do Planejamento, Orçamento e Gestão. Portaria Interministerial 22. Banco de professor equivalente. Brasília, DF, 2007b. Disponível em: <http://portal.mec.gov.br/arquivos/pdf/ professor_equivalente.pdf>. Acesso em: 5 dez. 2012.

BRASIL. Ministério da Educação. O Plano de Desenvolvimento da Educação: razões, princípios e programas. Brasília, DF, 2008. Disponível em: <http://portal.mec.gov.br/arquivos/livro/>. Acesso em: 15 abr. 2014.

BRASIL. Ministério da Educação. Análise sobre a Expansão das Universidades Federais 2003 a 2012. Brasília, DF, 2012, 55p. Relatório da Comissão Constituída pela Portaria no 126/2012. Disponível em: <http://portal.mec. gov.br/index.php?option=com_docman\&task=doc_download\&gid=12386\&ltemid=>. Acesso em: 12 set. 2013.

BRASIL. Lei no 13.005, de 25 de junho de 2014. Aprova o Plano Nacional de Educação - PNE e dá outras providências. Brasília, DF, 2014. Disponível em: <http://www.planalto.gov.br/CCIVIL_03/_Ato2011-2014/2014/Lei/ L13005.htm>. Acesso em: 30 jun. 2014.

CATANI, A. M.; OLIVEIRA, J. F. A educação superior. In: OLIVEIRA, R. P.; ADRIÃO, T. Organização do ensino no Brasil: níveis e modalidades na Constituição Federal e na LDB. São Paulo: Xamã, 2002. p. 77-88.

CHAUÍ, M. A universidade hoje. In: CHAUÍ, M. Escritos sobre a universidade. São Paulo: Editora UNESP, 2001. p.175-194.

CHAUÍ, M. A universidade pública sob nova perspectiva. Revista Brasileira de Educação, Rio de Janeiro, n. 24, p. 5-15, 2003. Disponível em: <http://www.scielo.br/pdf/rbedu/n24/n24a02.pdf>. Acesso em: 20 nov. 2012.

CORRAGIO, J. L. Propostas do Banco Mundial para a educação: sentido oculto ou problema de concepção. In: TOMASI, L., WARDE, M. J., HADDAD, S. O Banco Mundial e as políticas educacionais. São Paulo: Cortez, 2000. $75-121 \mathrm{p}$.

DOURADO, L. F. Reforma do Estado e as políticas para a educação superior no Brasil nos anos 90. Revista Educação e Sociedade, Campinas, v. 23, n. 80, p. 234-252, set. 2002. Disponível em: <http://www.cedes.unicamp. br>. Acesso em: 20 ago. 2013.

KRAWCZYK, N. A construção social das políticas educacionais no Brasil e na América Latina. In: KRAWCZYK, N.; CAMPOS, M.M.; HADDAD, S. O cenário educacional latino-americano no limiar do século XXI: reformas em debate. Campinas: Autores Associados, 2000. p. 1-11.

LIMA, A. B. Dez anos de LDB: anos de contínua reforma educacional. In: VIEIRA, M.; MARQUES, M.R.A. LDB: balanços e perspectivas para a educação brasileira. 2. ed. Campinas: Alínea, 2012. p. 51-70.

NAZARI, J. Programa de aceleração de estudos na rede estadual de ensino de Uberlândia, Minas Gerais: uma gestão focada nas exigências da produtividade. 2012. 179 f. Dissertação (Mestrado) - Universidade Federal de Uberlândia, Uberlândia, 2012.

PAOLI, M. C. Empresas e Responsabilidade social: os enredamentos da cidadania no Brasil. In: SANTOS, B. S. Democratizar a democracia: os caminhos da democracia participativa. Civilização Brasileira: Rio de Janeiro, 2002. p. 373-418.

RODRIGUES, M. M. A LDB e a avaliação institucional na educação superior: aproximando concepções. In: VIEIRA, M.; MARQUES, M.R.A. LDB: balanços e perspectivas para a educação brasileira. Campinas: Alínea, 2012. 2. ed. p. 159-172.

SGUISSARDI, V. Universidade brasileira no século XXI: desafios do presente. São Paulo: Cortez, 2009. 
SOARES, M. C. C. Banco Mundial: políticas e reformas. In: TOMMASI, L.; WARDE, M. J.; HADDAD, S. O Banco Mundial e as políticas educacionais. 4. ed. São Paulo: Cortez, 2003. p. 15-40.

ORGANIZAÇÃO DAS NAÇÕES UNIDAS PARA A EDUCAÇÃO, A CIÊNCIA E A CULTURA. Declaração mundial sobre educação superior: marco referencial de ação prioritária para a mudança e o desenvolvimento de Educação Superior. Paris, 1998.

Recebido em dezembro de 2014. Aprovado em outubro de 2015. 